\title{
Prevalence of total hip replacement: how much demand has been met?
}

\author{
M H Williams, J N Newton, S J Frankel, F Braddon, E Barclay, J A M Gray
}

\begin{abstract}
Objective - To determine the prevalence of completed elective total hip replacements in a defined elderly population.

Design - Cross sectional postal questionnaire survey with additional data and validation from general practice and hospital records.

Setting - Six general practices in the English counties of Avon, Somerset, and Oxfordshire.

Subjects - A total of 7806 patients aged 65 years and over $(94 \cdot 7 \%$ response).

Results - The overall prevalence $(95 \%$ confidence intervals) of elective total hip replacement was $5 \cdot 3(4 \cdot 8,5 \cdot 8) \%$. Age and sex specific prevalences were $2 \cdot 7$ $(2 \cdot 0,3 \cdot 5) \%$ in men and $4 \cdot 1(3 \cdot 3,4 \cdot 9) \%$ in women aged 65-74 years, and $5 \cdot 2$ $(4 \cdot 0,6 \cdot 5) \%$ in men and $8 \cdot 8(7 \cdot 6,10 \cdot 0) \%$ in women aged 75 years and over. Of the 415 patients who had received elective total hip replacement, $28 \cdot 2 \%$ had required bilateral surgery, $20 \%$ had received at least one operation privately, and $13 \%$ had required revision surgery.

Conclusion - Our results show an increased level of satisfied demand for total hip replacement in elderly people compared with earlier estimates. The increasing prevalence of hip replacement is an indicator of increasing potential demand for revision procedures. Population based surveys are required to establish the level of unmet demand for primary procedures. Differences in past surgical activity may be important in interpreting the wide variation in current surgical rates.
\end{abstract}

( $\mathcal{F}$ Epidemiol Community Health 1994;48:188-191)

Health Care

Evaluation Unit,

Department of

Epidemiology and

Public Health

Medicine, University

of Bristol, Canynge

Hall, Whiteladies

Road, Bristol BS8 2PR

M H Williams

S J Frankel

F Braddon

Department of Public Health Medicine,

Oxfordshire Health

Authority, Oxford

$\mathrm{J} N$ Newton

E Barclay

J A $M$ Gray

Correspondence to: Dr M H Williams.

Accepted for publication August 1993 commest of which is osteoarthritis. available evidence suggests that hip replacement is cost effective compared with many other treatments. ${ }^{1-4}$ Its very success has led to fears that the requirement for surgery will be overwhelming. ${ }^{5}$ Recently, however, it has been suggested that the quality of prosthetic implants and the skill of the surgeons may vary, leading to poorer outcomes in some patients, including a premature need for revision surgery. ${ }^{67}$

Before setting activity levels for total hip replacement or any other elective procedure, it is necessary to decide whether it is feasible to satisfy the population's requirement for surgery (that is, treat all those likely to benefit) or whether the aim is merely to ensure that those who are treated are those that will benefit most. The latter is sometimes a legitimate response to finite resources and can be achieved either by managing the waiting list or restricting the indications for which surgery is performed, both of which may currently be implicit practice in the UK. Unfortunately, there is only limited information concerning current levels of met and unmet demand for particular interventions on which to base these judgements. ${ }^{8}$ The assumption that demand, because of its elasticity, must consistently exceed supply remains unchallenged because of this uncertainty. ${ }^{9}$

The lack of knowledge of the requirement for total hip replacement surgery is a matter of particular concern as the Department of Health has made specific recommendations about the rate of hip replacement. Despite this national target of 1050 hip operations per million population per year, which was to be achieved by 1990, there has been considerable variation in the level of surgical activity between health regions and districts in England during the past decade. ${ }^{1011}$

In 1982, a comparison of the estimated requirement for total hip replacement surgery with the prevailing English regional surgical rates suggested that in some areas it might be possible for the number of operations to match the number of new cases of hip disease requiring surgery, once the backlog of these cases had been cleared. ${ }^{10}$ Current surgical rates now far exceed the 1982 estimate, yet waiting lists for total hip replacement persist, leading to claims that the NHS has failed to provide care for those that could benefit from it. ${ }^{1213}$

This study aims to establish the prevalence of completed total hip replacement, which is both an indicator of how much of the requirement for elective surgery has already been met, either by the NHS or the private sector, and the likely size of future demand for revision procedures, which is a function of the level and outcome of past surgical treatment.

\section{Subjects and methods}

In 1991, family health services authority (FHSA) registers were used to create lists of the names and addresses of 8166 subjects, aged 65 years and over, registered with six general 
practices in Avon, Somerset, and Oxfordshire. The survey population was later reduced to 7806 as 212 subjects were found to have moved beyond the FHSA boundaries and 148 had died.

A postal questionnaire was used to seek information on the following: whether respondents had received a total hip replacement; whether primary surgery was elective, for hip arthropathy, or whether it had followed a fracture of the hip; whether it had been performed privately or as an NHS procedure; and whether revision or conversion surgery had been necessary.

Response rates to the questionnaire varied between $91.4 \%$ and $98.9 \%$ for the six practices, with an overall response of $94.7 \%$.

To confirm the information given and the nature of any operation, the general practice records were inspected for all those reporting total hip replacement and this was supplemented by information from hospital records if data were absent or incomplete. In addition, the records of a $10 \%$ random sample of negative responders were checked, for validation purposes, as were the records of all non-responders. The level of ascertainment was therefore effectively $100 \%$ in all practices. No false negative replies were identified, but a small number of total hip replacements were picked up in non-responders. No false positive replies were found.

Patients included in the analysis were those who had undergone elective total hip replacement surgery for any indication, either as primary or revision/conversion procedures. Emergency procedures for fractured neck of femur which had not subsequently been revised electively were excluded.

ANALYSIS

Confidence intervals for the age specific prevalence rates were calculated using the formula for the standard error of a proportion based on the normal approximation of the Poisson distribution. When proportions were derived from less than 100 individuals, exact confidence intervals were obtained from standard tables. $^{14}$

\section{Results}

A total of 415 people with total hip replacements were identified, of whom 117 had received bilateral surgery. The overall prevalence $(95 \% \mathrm{CI})$ of total hip replacement in those aged 65 years and over was therefore $5 \cdot 3$ $(4 \cdot 8,5 \cdot 8) \%$. Total hip replacement was more common in women overall $(6 \cdot 4(5 \cdot 7,7 \cdot 1) \%)$ than in men $(3 \cdot 7(3 \cdot 1,4 \cdot 4) \%)$ and in each age group (see table 1). Twenty (16-24)\% of people with a total hip replacement had undergone at least one operation privately and 13 (9$16) \%$ had required at least one revision procedure (see table 2). The highest revision rate, $17(7-28) \%$, was found in men aged $65-74$ years.

Differences in total hip replacement prevalence rates between the practices were partly the result of age and sex differences, thus the age and sex standardised prevalences by practice (patient numbers) were less variable than the crude rates but still ranged from $4.3 \%(80)$ to $7 \cdot 1 \%$ (148). A substantial part of the remaining variation was the result of different rates of private surgery: the prevalence of NHS total hip replacement ranged from $3.8 \%$ (88) to $5.2 \%$ (109), while the prevalence of private total hip replacement ranged from $0.4 \%$ (8) to $1.9 \%$ (39). The general practice which had the highest rate of private surgery, however, also had the highest rate of NHS surgery.

\section{Discussion}

In ideal circumstances, the population re-

Table 1 Frequency and prevalence of total hip replacement (THR)

\begin{tabular}{|c|c|c|c|c|c|c|c|c|c|c|}
\hline & $\begin{array}{l}\text { Survey } \\
\text { population }\end{array}$ & $\begin{array}{l}\text { Unilateral THR } \\
\text { Prevalence } \\
(\%)\end{array}$ & $(95 \% C I)$ & $\begin{array}{l}\text { No of } \\
\text { patients }\end{array}$ & $\begin{array}{l}\text { Bilateral THR } \\
\text { Prevalence } \\
(\%)\end{array}$ & $(95 \% C D)$ & $\begin{array}{l}\text { No of } \\
\text { patients }\end{array}$ & $\begin{array}{l}\text { Any THR } \\
\text { Prevalence } \\
(\%)\end{array}$ & $(95 \% \mathrm{CI})$ & $\begin{array}{l}\text { No of } \\
\text { patients }\end{array}$ \\
\hline $\begin{array}{l}\text { Male: } \\
65-74 \text { y } \\
>74 \text { y }\end{array}$ & $\begin{array}{l}1906 \\
1262\end{array}$ & $\begin{array}{l}2 \cdot 0 \\
3 \cdot 4\end{array}$ & $\begin{array}{l}(1 \cdot 4,2 \cdot 6) \\
(2 \cdot 4,4 \cdot 4)\end{array}$ & $\begin{array}{l}38 \\
43\end{array}$ & $\begin{array}{l}0.7 \\
1.8\end{array}$ & $\begin{array}{l}(0 \cdot 4,1 \cdot 1) \\
(1 \cdot 1,2 \cdot 6)\end{array}$ & $\begin{array}{l}14 \\
23\end{array}$ & $\begin{array}{l}2 \cdot 7 \\
5 \cdot 2\end{array}$ & $\begin{array}{l}(2 \cdot 0,3 \cdot 5) \\
(4 \cdot 0,6 \cdot 5)\end{array}$ & $\begin{array}{l}52 \\
66\end{array}$ \\
\hline $\begin{array}{l}\text { Female: } \\
65-74 \text { y } \\
>74 \mathrm{y}\end{array}$ & $\begin{array}{l}2341 \\
2297\end{array}$ & $\begin{array}{l}2 \cdot 7 \\
6 \cdot 7\end{array}$ & $\begin{array}{l}(2 \cdot 1,3 \cdot 4) \\
(5 \cdot 6,7 \cdot 7)\end{array}$ & $\begin{array}{r}64 \\
153\end{array}$ & $\begin{array}{l}1 \cdot 3 \\
2 \cdot 1\end{array}$ & $\begin{array}{l}(0.9,1.8) \\
(1.5,2 \cdot 7)\end{array}$ & $\begin{array}{l}31 \\
49\end{array}$ & $\begin{array}{l}4 \cdot 1 \\
8 \cdot 8\end{array}$ & $\begin{array}{l}(3 \cdot 3,4 \cdot 9) \\
(7 \cdot 6,10 \cdot 0)\end{array}$ & $\begin{array}{r}95 \\
202\end{array}$ \\
\hline Total & 7806 & $3 \cdot 8$ & $(3 \cdot 4,4 \cdot 2)$ & 298 & 1.5 & $(1 \cdot 2,1 \cdot 8)$ & 117 & $5 \cdot 3$ & $(4 \cdot 8,5 \cdot 8)$ & 415 \\
\hline
\end{tabular}

Table 2 Private and revision procedures

\begin{tabular}{|c|c|c|c|c|c|c|c|}
\hline & \multirow{2}{*}{$\begin{array}{l}\text { Patients with } \\
\text { THR }\end{array}$} & \multicolumn{3}{|c|}{ Patients with at least one private operation } & \multicolumn{3}{|c|}{ Patients with at least one revision operation } \\
\hline & & $\%$ & $(95 \% C I)$ & No of patients & $\%$ & $(95 \% C I)$ & No of patients \\
\hline $\begin{array}{l}\text { Male: } \\
65-74 \text { y } \\
>74 \text { y }\end{array}$ & $\begin{array}{l}52 \\
66\end{array}$ & $\begin{array}{l}17 \\
21\end{array}$ & $\begin{array}{l}(7,28) \\
(11,31)\end{array}$ & $\begin{array}{r}9 \\
14\end{array}$ & $\begin{array}{l}17 \\
15\end{array}$ & $\begin{array}{l}(7,28) \\
(6,24)\end{array}$ & $\begin{array}{r}9 \\
10\end{array}$ \\
\hline $\begin{array}{l}\text { Female: } \\
65-74 \text { y } \\
>74 \mathrm{y}\end{array}$ & $\begin{array}{r}95 \\
202\end{array}$ & $\begin{array}{l}24 \\
18\end{array}$ & $\begin{array}{l}(16,33) \\
(12,23)\end{array}$ & $\begin{array}{l}23 \\
36\end{array}$ & $\begin{array}{r}6 \\
13\end{array}$ & $\begin{array}{l}(1,11) \\
(9,18)\end{array}$ & $\begin{array}{r}6 \\
27\end{array}$ \\
\hline Total & 415 & 20 & $(16,24)$ & 82 & 13 & $(9,16)$ & 52 \\
\hline
\end{tabular}


quirement for elective total hip replacement surgery would be estimated by comparing the prevalence and incidence of hip arthropathies with standard indications for surgery. ${ }^{11}$ Such indications have not been defined in the United Kingdom and variation in the level of satisfied demand is likely to be partially explained by differences in thresholds for elective surgery in the past. In addition, current estimates of the prevalence of symptomatic arthropathies of the hip reflect not only the distribution of morbidity in the community but also the success of past total hip replacement surgical activity.

Although the prevalence of met demand for certain elective surgical operations has been measured in the past, ${ }^{15}$ only one British survey has provided such information for total hip replacement. ${ }^{16}$ In that study, performed in 1977, Wilcock estimated that in an Oxfordshire population aged 66 years and over, $0.7 \%$ of the population had already received elective total hip replacement surgery and a further $1.8 \%$ would be expected to benefit from the procedure.

The 1988 National Health Interview Survey in the USA showed a prevalence $(95 \% \mathrm{CI})$ of artificial hip implants of $11.3(8.4,14 \cdot 2) \%$ in adults aged $65-74$ years and $23.9(18 \cdot 4,29 \cdot 4) \%$ in those aged 75 years and over. ${ }^{17}$ That survey obtained data from over 28000 people aged over 65 years but no distinction was made between elective surgery and emergency hip surgery for fracture. Also, data were obtained by questionnaire without validation of the results. In the study reported here all positive responses for elective or emergency primary and revision hip surgery were checked against information held in the patients' general practice or hospital records and information was obtained on all non-responders from the same sources.

The prevalence of total hip replacement in this study population $(5 \cdot 3 \%)$ is seven times greater than that which Wilcock found in 1977. It is also more than twice Wilcock's estimate of the total requirement for the operation $(2.5 \%)$, although the latter was made at a time when surgical and anaesthetic techniques were less developed and indications for surgery more conservative than they are now. Wilcock may also have underestimated the requirement for elective surgery because he restricted his study to osteoarthritis of the hip, which accounted for only $76 \%$ of cases in a recent elective total hip replacement case series. ${ }^{18}$ The prevalence rate for completed total hip replacements is now comparable with previous estimates of the prevalence of hip arthritis in the population. ${ }^{11}$ Four British studies in adults over 65 years, conducted before total hip replacement surgery was routine, found prevalence rates ranging from $3 \%$ to $5 \cdot 6 \%,{ }^{16}$ while Danielsson, in Sweden in 1966, reported that the overall prevalence of hip osteoarthritis was $6 \% .{ }^{19}$ Comparisons with rates of total hip replacement are confounded, however, by lack of information on the prevalence of symptomatic arthritis from these studies which focussed on radiological changes. The difficulties encountered in defining and grading osteoarthritis of the hip in epidemiological studies have been described. ${ }^{20}$ There is a poor correlation between symptoms and radiological change in osteoarthritis of the hip.

Far more attention continues to be given to the size of waiting lists than to any other indicator of surgical activity. Waiting lists are not necessarily helpful when considering whether the requirement for surgery is being satisfied. For example, there is no correlation between current levels of surgical activity and waiting times. ${ }^{11}$ An alternative approach was taken in two studies which have shown that the variation in total hip replacement rates between district health authority populations has decreased as the operation has become more widely available. ${ }^{2122}$ This was interpreted as a sign that the level of unmet need for total hip replacement was being reduced as the prevalence of met demand was increasing irrespective of any change in waiting lists.

The number of patients requiring revision procedures is also increasing. In England, the proportion of elective total hip replacements which were revisions of previous surgery almost tripled between $1980(4 \cdot 1 \%)$ and 1989 $90(12 \cdot 1 \%) .{ }^{11}$ In the study reported here, $13 \%$ of people with a total hip replacement had already undergone revision surgery and the high overall prevalence of total hip replacement suggests that the need for revision surgery will continue to increase. The cost of a revision operation has been estimated to be as much as three times that of a primary procedure. ${ }^{2324}$

A population survey of the kind reported here is one of the very few ways of investigating the contribution that the private sector makes to satisfying the demand for surgery, activity data not being generally available from private hospitals. ${ }^{11}$ The finding that one in five patients had at least one operation performed privately is consistent with the only previously published estimate of the proportion of private hip replacements $(27 \cdot 7 \%) .{ }^{25}$

We conclude that considerable progress has been made since 1977 towards satisfying the demand for total hip replacement despite the fact that waiting lists persist. The lack of population studies of patients that could benefit from joint replacement, judged by current criteria, means that it is still not possible to say how much remains to be done in order to satisfy demand. The results of surveys of the indications for elective surgery are urgently required. ${ }^{11}$

We wish to thank participating general practitioners in Avon, Oxfordshire, and Somerset (particularly Drs D Jewell, $M$ Whitfield, R Rivett, A Chivers, W Couldrick, and I Hughes) for allowing us access to their patients, and our anonymous for allowing us access to their
referees for their comments.

1 Liang MH, Cullen KE, Larson MG, et al. Cost-effectiveness of total joint arthroplasty. Arthritis Rheum 1986;29(8):937-43.

2 Eftekhar NS. Long term results of cemented hip arthroplasty. Clin Orthop 1987;225:207-17.

3 Harries WH, Sledge CB. Total hip and total knee replacement (first of two parts). $N$ Engl f Med 1990;323:725-31. ment (first of two parts). N Engl f Med 1990;323:725-31.
4 Cushner F, Friedman RJ. Economic impact of total hip arthroplasty. South Med f 1988;81(11):1379-81.

5 Bulstrode CJK. Keeping up with orthopaedic epidemics. BMF 1987;295:514. 
6 Wearne P, Jones J. Shooting at the hip. The Guardian, 23 February 1993

7 Bulstrode CJK, Murray DW, Carr AJ, Pynsent PB, Carter SR. Designer hips. BMF 1993;306:732-3.

8 Frankel SJ. The epidemiology of indications. $f$ Epidemiol Community Health 1991;45(4):257-9.

9 Frankel SJ. Health needs, health care requirements, and the myth of infinite demand. Lancet 1991;337:1588-9.

10 Office of Health Economics. Hip replacement and the NHS. London: OHE, 1982.

11 Williams MH, Frankel SJ, Nanchahal K, Coast J, Donovan J. An epidemiologically based needs assessment: total hip J. An epidemiologically based needs assessment: total hip replacement surgery (2nd ed).

12 Davidge M, Harley M, Vickerstaff L, Yates J. The anatomy of large inpatient waiting lists. Lancet 1987; i:794-6.

13 Duthie RB. Orthopaedic services: waiting times for outpatient appointments and inpatient treatment. London: HMSO, 1981.

14 Lentner C, ed. Geigy scientific tables. Vol 2, 8th ed. Basle: Ciba Geigy, 1982:89-104

15 Coulter A, McPherson K. Socioeconomic variations in the use of common surgical operations. BMF 1985;291:183-7.

16 Wilcock GK. The prevalence of osteoarthritis of the hip requiring total hip replacement in the elderly. Int $\mathcal{f}$ Epidemiol 1979;8(3):247-50.

17 Sharkness CM, Hamburger S, Moore RM, Kaczmarek RG.
Prevalence of artificial hip implants and use of health services by recipients. Public Health Rep 1993;108(1):705.

18 Madhok R, Lewallen DG, Wallrichs SL, Ilstrup DM Kurland RL, Melton LJ III. Trends in utilization of primary total hip arthroplasty 1969-90: a populationbased study in Olmsted County, Minnesota. Mayo Clinic Proc 1993;68:11-18.

19 Danielsson L. Incidence of osteoarthritis of the hip. Clin Orthop 1966;45:67-72.

20 Croft P, Cooper C, Wickham C, Coggan D. Defining osteoarthritis of the hip for epidemiologic studies. Am $\mathcal{F}$

21 Seagroatt V, Tan HS, Goldacre M, Bulstrode CJK, Nugent I, Gill L. Elective total hip replacement: incidence, emergency readmission rate and postoperative mortality BMf 1991;303:1431-5.

22 Rajaratnam G, Black NA, Dalziel $M$. Total hip replacements in the National Health Service: is need being met? f Pub Health Med 1990;12:56-9.

23 Dreghorn CR, Hamblen DL. Revision arthroplasty: a high price to pay. BMF 1989;298:648-9.

24 Treacy R, Carter S, Grigoris P, Pynsent P. Failed hip replacements (letter). BMF 1992;304:317.

25 Nicholl JP, Beeby NR, Williams BT. Role of the private sector in elective surgery in England and Wales, 1986. $B M \mathcal{F}$ 1989;298:243-7. 